\title{
Quality of life after total laryngectomy: impact of different vocal rehabilitation methods in a middle income country
}

\author{
F. G. R. Souza ${ }^{\text {* }}$, I. C. Santos², A. Bergmann ${ }^{3}$, L. C. S. Thuler ${ }^{3}$, A. S. Freitas ${ }^{4}$, E. Q. Freitas ${ }^{2}$ and F. L. Dias ${ }^{2}$
}

\begin{abstract}
Introduction: The impact of advanced laryngeal cancer and its extensive surgical treatments cause significant morbidity for these patients. Total laryngectomy impacts essential functions such as breathing, communication and swallowing, and may influence the quality of life as well as affecting the social life of laryngeal cancer patients.

Objective: Describe the quality of life and analyze the factors associated with the reduced quality of life in patients who have undergone total laryngectomy.

Method: Observational cross-sectional study was carried out to evaluate the quality of life of patients who had undergone total laryngectomy due to laryngeal cancer. The fourth version of the UW-QOL Quality of Life Assessment Questionnaire from Washington University, validated for Portuguese, was used.

Results: The study population was 95 patients, and the mean composite score of the QOL was 80.4. In the subjective domains the majority of the patients (38.9\%) reported they felt much better at present compared to the month before being diagnosed with cancer. When questioned about how they evaluated their health-related quality of life, there was a predominance of those who considered it good (43.2\%), and most considered they had a good quality of life (46.3\%) considering personal well-being. The overall quality of life was considered good to excellent by $83.2 \%$ of the patients. Patients with tracheoesophageal prosthesis reported a better quality of life, compared to patients using an electrolarynx or esophageal voice.
\end{abstract}

Conclusion: The high mean value of the composite score for quality of life revealed that the patients assessed their quality of life positively. The absence of vocal emission was the only variable associated with a lower quality of life within the composite score according to the UW-QOL questionnaire.

Keywords: Health-related quality of life, Head and neck cancer, UW-QOL

\section{Introduction}

Laryngeal cancer accounts for approximately $25 \%$ of the malignant neoplasms in the head and neck region and $2 \%$ of all malignancies. Also it causes 83,000 deaths per year worldwide [1]. Estimates of around 6390 new cases of laryngeal cancer in men are expected in Brazil in the 2018-2019 period and 1280 new cases in women. The estimated risk for men is 6.17 cases per 100,000 and 1.20 per 100,000 for women [2].

\footnotetext{
* Correspondence: nandars@hotmail.com

${ }^{1}$ Researcher Psychologist from Department of Head and Neck Surgery, Brazilian National Cancer Institute, INCA, Praça da Cruz Vermelha, 23, Rio de Janeiro 20230-130, Brazil

Full list of author information is available at the end of the article
}

The impact of advanced laryngeal cancer and its extensive surgical treatments cause significant morbidity for these patients. Total laryngectomy impacts essential functions such as breathing, communication and swallowing, and may influence the quality of life as well as affecting the social life of laryngeal cancer patients [3]. There are three different methods to carry out voice rehabilitation: esophageal voice, electrolarynx and a tracheoesophageal phonatory prosthesis. The rehabilitation of the voice using a tracheoesophageal prosthesis is currently considered the gold standard because it provides better vocal quality and longer phonation time than the other methods [4].

(C) The Author(s). 2020 Open Access This article is distributed under the terms of the Creative Commons Attribution 4.0 International License (http://creativecommons.org/licenses/by/4.0/), which permits unrestricted use, distribution, and reproduction in any medium, provided you give appropriate credit to the original author(s) and the source, provide a link to the Creative Commons license, and indicate if changes were made. The Creative Commons Public Domain Dedication waiver (http://creativecommons.org/publicdomain/zero/1.0/) applies to the data made available in this article, unless otherwise stated. 
The World Health Organization (WHO) defines quality of life as "the individual's perception of their position in life in the context of the culture and value systems in which they live, and in relation to their goals, expectations, standards and concerns." [5] In research, the quality of life assessment tools are important tools to measure the effect of these health treatments on the lives of patients, as well as providing the feedback of patient experiences in a structured way [6].

Today, there are several specific instruments, which have been developed in other countries, available to assess the quality of life in patients with head and neck cancer. In this study, the fourth version of the University of Washington Quality of Life Questionnaire (UWQOL) was used. This questionnaire provides a simple measure of health-related quality of life, and can be used for head and neck cancer patients. In clinical use it provides data concerning patients' perceptions of the different types of treatments and can identify patients who are worse off and would benefit from a more appropriate intervention $[7,8]$.

In addition to having three general questions about their overall health-related quality of life, it is the only one with an open question for patients to comment on. It is considered a concise instrument, easy to understand and quick to apply [8].

There are also other questionnaires related to head and neck functions that are frequently used. FACT-HN (version 4.0) is a multidimensional and self-administered questionnaire with 5 domains: physical, social, familial, emotional, functional, and 12 questions specifically related to head and neck cancer. The instrument is concise and easy to apply and is sensitive to the evaluation of cancer patients in the acute and late phases of treatment; and also includes questions that are non-specific to the disease and treatment [9].

The QLQ-H\&N35, which was developed by the European Organization for Research and Treatment of Cancer (EORTC), is a questionnaire widely used to evaluate the quality of life of patients with head and neck cancer. The EORTC QLQ-H\&N35 should be applied together with the EORTC QLQ-C30 questionnaire, which evaluates the global quality of life in cancer patients in general; thus the two questionnaires appraise both global and specific domains in these patients. This questionnaire is considered to be sensitive to changes in the clinical staging of the patients; however it is much longer than the other QOL questionnaires for such patients [10].

The health-related quality of life of patients treated with total laryngectomy tends to decrease during treatment and stabilizes at around 12 months after surgery. These patients usually have a good long-term healthrelated quality of life following treatment despite the fact that total laryngectomy has a permanent and significant impacts on swallowing and speech [3].

This article aims to describe the quality of life and analyze the factors associated with the reduced quality of life in patients who have undergone total laryngectomy.

\section{Material and methods}

In this work an observational cross-sectional study was carried out to evaluate the quality of life of patients who had undergone total laryngectomy due to laryngeal cancer.

The patients included in this study were those who were registered at the Brazilian National Cancer Institute from 2004 to 2012, with a confirmed histology of squamous cell carcinoma (SCC) of the larynx, in stages III and IV, with or without extension to the hypopharynx, who had undergone total laryngectomy and neck dissection, with or without adjuvant radiotherapy. The following individuals were excluded: patients under 18 years old; those hospitalized in the period of data collection; individuals who could not be contacted by telephone; those who did not attend the outpatient appointments; patients with the disease still active; and those who had undergone surgical treatment less than 6 months previously. Eligible patients who signed a Free and Informed Consent Term were interviewed consecutively from December 2009 to January 2013. The study was approved by the Ethics and Research Committee of the National Cancer Institute under number 96/09.

The fourth version of the UW-QOL Quality of Life Assessment Questionnaire from Washington University, validated for Brazilians, was used [11]. It has twelve question domains related to specific head and neck functions as well as those related to activity, recreation, pain, mood and anxiety. Each domain has three to five response options with scores ranging from 0 (worst) to 100 (best) that can be appraised individually or by the total score (composed of the mean of the twelve domains). There are also three subjective questions that do not have specific scores, and refer to comparisons between patients or groups of patients [11].

This research was carried out following the guidelines of Weymuller et al. for studies performed at a single institution [6]. The data collected included descriptive and independent variables related to socio-demographic characteristics (age, gender, race, marital status, educational level), clinical status (clinical staging TNM, 2017; topography of the ICD-O tumor), and treatments (type of surgery, radiotherapy, chemotherapy, and speech and language rehabilitation) [12].

A descriptive study of the study population was carried out, using the means and standard deviation for the continuous variables and frequency distribution for the categorical variables. The Kolmogorov-Smirnov test was 
used to evaluate the normal distribution of the quality of life scores and the independent quantitative variables. A dispersion diagram was performed to evaluate the linearity between the outcome and the independent quantitative variables. As the quantitative independent variables did not present a normal distribution, they were categorized according to a theoretical reference [13].

To evaluate the association between the independent variables and the quality of life domain scores, the differences between the means of each score were calculated, and then the statistical difference was obtained by analysis of variance with ANOVA and nonparametric Tukey tests. A $5 \%$ level of significance was used.

All analyzes were carried out using the SPSS 21.0 program. (IBM, São Paulo).

\section{Results}

The results were based on a total of 95 laryngeal cancer patients with a mean age of 57.7 years old $( \pm 9.0)$, a mean time after surgery of 47.5 months $( \pm 42.2)$, and a mean UW-QOL composite score of 80.4.

The study population was predominantly male (90.5\%), with a low educational level (51.6\%), white (65.3\%), and at the time of the interview lived with a partner $(70.5 \%)$, presented clinical staging IV (64.2\%) and had undergone radiotherapy $(87.4 \%)$. The majority of the patients had undergone total laryngectomy and cervical emptying (92.6\%), predominantly rehabilitated with a tracheoesophageal prosthesis (43.2\%), followed by electrolarynx (33.7\%), and at the interview with vocal emission (85.3\%) (Table 1).

Table 2 shows the results of the objective domains of UW-QOL. The mean composite score of the QOL was 80.4. In the subjective domains the majority of the patients (38.9\%) reported they felt much better at present compared to the month before being diagnosed with cancer. When questioned about how they evaluated their health-related quality of life, there was a predominance of those who considered it good (43.2\%), and most considered they had a good quality of life $(46.3 \%)$ considering personal well-being. The overall quality of life was considered good to excellent by $83.2 \%$ of the patients (Table 3).

The mean scores of the domains in the UW-QOL questionnaire for the clinical and demographic variables of the patients who had suffered advanced laryngeal malignancies are described in Table 4 . Clinically the men presented better scores in most domains than the women and there was a statistically significant difference in the humor domain $(p=0.003)$. Those who lived without a partner reported a better clinical and statistical score for the activity domain $(p=0.033)$.

Patients who had undergone surgery more than 2 years before the date of the interview presented better quality of
Table 1 Demographic and Clinical Characteristics of the Patients Cohort $(n=95)$

\begin{tabular}{|c|c|}
\hline Variable & No (\%) \\
\hline \multicolumn{2}{|l|}{ Sex } \\
\hline Male & $86(90,5)$ \\
\hline Female & $9(9,5)$ \\
\hline \multicolumn{2}{|l|}{ Education, y } \\
\hline $1-7$ & $49(51,6)$ \\
\hline$\geq 8$ & $42(44,2)$ \\
\hline No information & $4(4,2)$ \\
\hline \multicolumn{2}{|l|}{ Ethnic Group } \\
\hline White (caucasian) & $62(65,3)$ \\
\hline Others & $29(30,5)$ \\
\hline No information & $4(4,2)$ \\
\hline \multicolumn{2}{|l|}{ Age, y } \\
\hline$\leq 60$ & $56(59,6)$ \\
\hline$>60$ & $38(40,4)$ \\
\hline \multicolumn{2}{|l|}{$67(70,5)$} \\
\hline \multicolumn{2}{|l|}{$24(25,3)$} \\
\hline \multicolumn{2}{|l|}{$4(4,2)$} \\
\hline \multicolumn{2}{|l|}{ Marital Status } \\
\hline \multicolumn{2}{|l|}{ Married } \\
\hline \multicolumn{2}{|l|}{ Single } \\
\hline \multicolumn{2}{|l|}{ No information } \\
\hline \multicolumn{2}{|l|}{ Time since Total Laryngectomy, y } \\
\hline$\leq 2$ & $31(32,6)$ \\
\hline$>2$ & $64(67,4)$ \\
\hline \multicolumn{2}{|l|}{ T Stage } \\
\hline III & $34(35,8)$ \\
\hline IV & $61(64,2)$ \\
\hline \multicolumn{2}{|l|}{ Adjuvant Treatment } \\
\hline No & $4(4,2)$ \\
\hline Radiotherapy & $83(87,4)$ \\
\hline Radiotherapy + Chemotherapy & $8(8,4)$ \\
\hline \multicolumn{2}{|l|}{ Tumor Site } \\
\hline Larynx & $91(95,8)$ \\
\hline Larynx and Hypopharynx & $4(4,2)$ \\
\hline \multicolumn{2}{|l|}{ Surgery } \\
\hline Total Laryngectomy + Neck Dissection & $88(92,6)$ \\
\hline Total Laryngectomy + Neck Dissection + Pharyngectomy & $7(7,4)$ \\
\hline \multicolumn{2}{|l|}{ Speech Therapy } \\
\hline Esophageal Speech & $22(23,2)$ \\
\hline Artificial Larynx & $32(33,7)$ \\
\hline Tracheoesophageal Speech & $41(43,2)$ \\
\hline \multicolumn{2}{|l|}{ Voice Emission } \\
\hline No & $14(14,7)$ \\
\hline Yes & $81(85,3)$ \\
\hline
\end{tabular}


Table 2 Scores for the University of Washington Quality of Life Questionnaire $(n=95)$

\begin{tabular}{|c|c|c|}
\hline UW-QOLv4 Domain & Categories & $n(\%)$ \\
\hline \multirow[t]{5}{*}{ Pain } & I have severe pain, not controlled by medication & $0(0,0)$ \\
\hline & I have severe pain controlled only by prescription medicine & $0(0,0)$ \\
\hline & I have moderate pain - requires regular medication & $16(16,8)$ \\
\hline & There is mild pain not needing medication & $13(13,7)$ \\
\hline & I have no pain & $66(69,5)$ \\
\hline \multirow[t]{5}{*}{ Appearance } & I cannot be with people due to my appearance & $1(1,1)$ \\
\hline & I feel significantly disfigured and limit my activities due to my appearance & $0(0,0)$ \\
\hline & My appearance bothers me but I remain active & $11(11,6)$ \\
\hline & The change in my appearance is minor & $49(51,6)$ \\
\hline & There is no change in my appearance & $34(35,8)$ \\
\hline \multirow[t]{5}{*}{ Activity } & I am usually in bed or chair and don't leave home & $0(0,0)$ \\
\hline & I don't go out because I don't have the strength & $0(0,0)$ \\
\hline & I am often tired and have slowed down my activities although I still get out & $13(13,7)$ \\
\hline & There are times when I can't keep up my old pace, but not often & $40(42,1)$ \\
\hline & I am as active as I have ever been. & $42(44,2)$ \\
\hline \multirow[t]{5}{*}{ Recreation } & I can't do anything enjoyable & $0(0,0)$ \\
\hline & There are severe limitations to what I can do, mostly I stay at home and watch TV & $6(6,3)$ \\
\hline & There are many times when I wish I could get out more, but I'm not up to it & $10(10,5)$ \\
\hline & There are a few things I can't do but I still get out and enjoy life & $35(36,8)$ \\
\hline & There are no limitations to recreation at home or away from home & $44(46,3)$ \\
\hline \multirow[t]{4}{*}{ Swallowing } & I cannot swallow because it "goes down the wrong way" and chokes me & $2(2,1)$ \\
\hline & I can only swallow liquid food & $3(3,2)$ \\
\hline & I cannot swallow certain solid foods & $40(42,1)$ \\
\hline & I can swallow as well as ever & $50(52,6)$ \\
\hline \multirow[t]{3}{*}{ Chewing } & I cannot even chew soft solids & $2(2,1)$ \\
\hline & I can eat soft solids but cannot chew some foods & $25(26,3)$ \\
\hline & I can chew as well as ever & $68(71,6)$ \\
\hline \multirow[t]{4}{*}{ Speech } & I cannot be understood & $0(0)$ \\
\hline & Only my family and friends can understand me. & $27(28,4)$ \\
\hline & I have difficulty saying some words but I can be understood over the phone & $58(61,1)$ \\
\hline & My speech is the same as always & $10(10,5)$ \\
\hline \multirow[t]{4}{*}{ Shoulder } & I cannot work or do my hobbies due to problems with my shoulder & $1(1,1)$ \\
\hline & Pain or weakness in my shoulder has caused me to change my work / hobbies & $9(9,5)$ \\
\hline & My shoulder is stiff but it has not affected my activity or strength & $23(24,2)$ \\
\hline & I have no problem with my shoulder & $62(65,3)$ \\
\hline \multirow[t]{4}{*}{ Taste } & I cannot taste any foods & $2(2,1)$ \\
\hline & I can taste some foods & $14(14,7)$ \\
\hline & I can taste most foods normally & $22(23,2)$ \\
\hline & I can taste food normally & $57(60,0)$ \\
\hline \multirow[t]{4}{*}{ Saliva } & I have no saliva & $1(1,1)$ \\
\hline & I have too little saliva & $17(17,9)$ \\
\hline & I can taste most foods normally & $30(31,6)$ \\
\hline & I can taste food normally & $47(49,5)$ \\
\hline
\end{tabular}


Table 2 Scores for the University of Washington Quality of Life Questionnaire $(n=95)$ (Continued)

\begin{tabular}{lll}
\hline UW-QOLv4 Domain & Categories & $n(\%)$ \\
\hline Mood & I am extremely depressed about my cancer & $0(0,0)$ \\
& I am somewhat depressed about my cancer & $9(9,5)$ \\
& I am neither in a good mood nor depressed about my cancer & $10(10,5)$ \\
& My mood is generally good and only occasionally affected by my cancer & $26(27,4)$ \\
& My mood is excellent and unaffected by my cancer & $50(52,6)$ \\
Anxiety & I am very anxious about my cancer & $2(2,1)$ \\
& I am anxious about my cancer & $5(5,3)$ \\
& I am a little anxious about my cancer & $25(26,3)$ \\
& I am not anxious about my cancer & $63(66,3)$ \\
\hline
\end{tabular}

life scores with statistical significance for the speech domain $(p=0.006)$. Comparing those who had undergone total laryngectomy and neck dissection with or without pharyngectomy, those who performed the more extensive surgery had a better score. There was a statistical significance regarding speech and language rehabilitation in the speech domain $(p \leq 0.001)$ : the patients with tracheoesophageal prosthesis reported a better quality of life, compared to patients using an electrolarynx or esophageal voice.

In the voice domain, there was a statistical significance in the swallowing $(p=0.019)$, speech $(p \leq 0.001)$, taste $(p=0.041)$, and anxiety $(p=0.003)$ domains and in the composite score $(p=0.007)$ for the individuals with vocal emission who described how their quality of life had improved. There was a difference of 9.48 points in the composite score between the patients with vocal emission (81.80) and without vocal emission (72.32).

\section{Discussion}

This was the first quality of life study on patients who had undergone total laryngectomy, evaluated by the UW-QOL according to the speech and language rehabilitation center at the Brazilian National Cancer Institute. Advanced laryngeal malignancies and their extensive surgical treatments can result in various dysfunctions, with negative repercussions on the quality of life of such patients. A total of 95 patients with laryngeal cancer who had undergone total laryngectomy were included in this study. The results show that, in relation to the demographic and clinical characteristics, the study population was predominantly male ( 8 men for each woman), less than 60 years old, white, of low educational level, and at the time of the interview lived with a companion, had clinical staging IV, and had undergone radiotherapy. Similar results

Table 3 Patients Classification of Global Quality of Life (QOL)

\begin{tabular}{|c|c|c|}
\hline UW-QOLv4 Global Questions & Categories & n (\%) \\
\hline \multirow{5}{*}{$\begin{array}{l}\text { Compared to the month before you developed cancer, how would you rate your health-related } \\
\text { quality of life? }\end{array}$} & Much better & $37(38,9)$ \\
\hline & Somewhat better & $22(23,2)$ \\
\hline & About the same & $27(28,4)$ \\
\hline & Somewhat worse & $7(7,4)$ \\
\hline & Much worse & $2(2,1)$ \\
\hline \multirow[t]{6}{*}{ In general, would you say your health-related quality of life during the past 7 days has been: } & Outstanding & $18(18,9)$ \\
\hline & Very good & $16(16,8)$ \\
\hline & Good & $41(43,2)$ \\
\hline & Fair & $20(21,1)$ \\
\hline & Poor & $0(0,0)$ \\
\hline & Very poor & $0(0,0)$ \\
\hline \multirow{6}{*}{$\begin{array}{l}\text { Overall quality of life includes not only physical and mental health, but also many other factors, } \\
\text { such as family, friends, spirituality, or personal leisure activities that are important to your enjoyment } \\
\text { of life. Considering everything in your life that contributes to your personal well-being, rate your } \\
\text { overall quality of life during the past } 7 \text { days. }\end{array}$} & Outstanding & $20(21,1)$ \\
\hline & Very good & $15(15,8)$ \\
\hline & Good & $44(46,3)$ \\
\hline & Fair & $16(16,8)$ \\
\hline & Poor & $0(0,0)$ \\
\hline & Very poor & $0(0,0)$ \\
\hline
\end{tabular}




\begin{tabular}{|c|c|c|c|c|c|c|c|c|c|}
\hline 雨 & 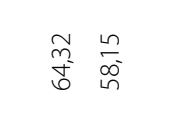 & $\frac{\bar{\gamma}}{8} \frac{\mathrm{g}}{\bar{\sigma}}$ & 害合 & 美器 & & & 焉登 & & $\frac{8}{8} 8$ \\
\hline & $\frac{9}{8}$ & 善 & $\overline{\bar{s}}$ & 罟 & $\frac{8}{8}$ & 善 & $\frac{\mathrm{m}}{\mathrm{g}}$ & $\bar{s}$ & 愛 \\
\hline 8 & 雷就 & 畐尊 & 器器 & 骨器 & 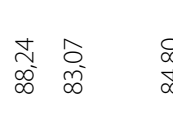 & 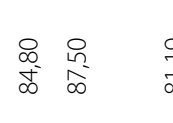 & 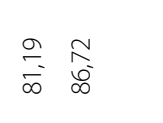 & 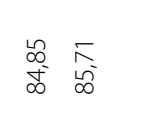 & 㝓棸 \\
\hline & $\frac{8}{8}$ & 气 & 今े & $\frac{\mathrm{g}}{\mathrm{s}} \mathrm{z}$ & $\frac{8}{\partial} \frac{8}{3}$ & 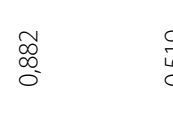 & $\frac{\mathrm{g}}{\mathrm{g}}$ & ริ & 喜 \\
\hline 串 & 좋 & 员吾 & 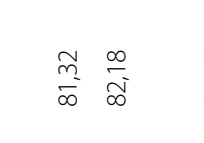 & $\frac{x^{2}}{8}$ & 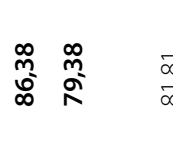 & 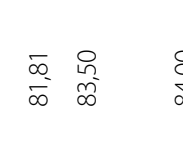 & 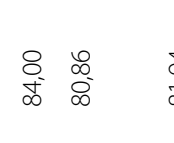 & 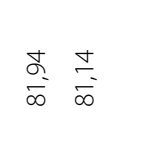 & 呟䜌 \\
\hline & 哭 & $\tilde{y}$ & $\frac{\frac{2}{\partial}}{\partial}$ & $\bar{z}$ & $\frac{5}{5}$ & $\overline{8}$ & 骂 & 高 & 孚 \\
\hline 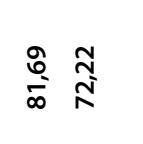 & 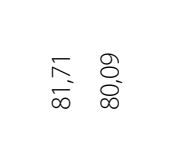 & 是昆 & 䇺莡 & $\frac{7}{\partial} \bar{z} \bar{z}$ & 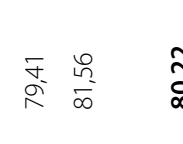 & 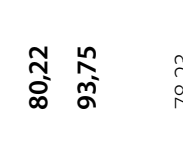 & 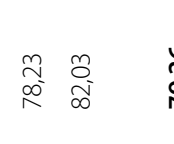 & 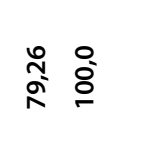 & 罚高 \\
\hline$\frac{1}{\delta}$ & 善 & $\frac{\mathrm{g}}{\mathrm{g}}$ & 券 & 咅 & 约 & $\frac{8}{8}$ & 舘 & $\bar{g}$ & 畄 \\
\hline 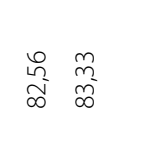 & ำ & 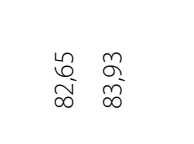 & 䎹言 & 촣ำ & 㛭是 & 독 & 㹎全 & 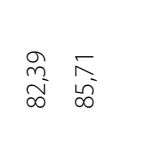 & ำ음 \\
\hline : & $\frac{8}{5}$ & $\frac{8}{8}$ & 乡 & 善 & $\frac{5}{3}$ & 产 & 8 & $\frac{8}{\partial}$ & a \\
\hline 票影 & $\frac{7}{2} \frac{2}{3}$ & $\frac{\circ}{\frac{O}{8}} \frac{\mathrm{g}}{\mathrm{z}}$ & $\frac{2}{\bar{\Phi}} \overline{\bar{x}}$ & 㝘产 & 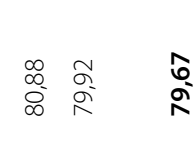 & 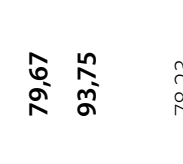 & 累哭 & 参脸 & 울 愛 \\
\hline$\frac{1}{8}$ & $\overline{\bar{g}}$ & 8 & $\bar{\xi}$ & 8 & $\frac{5}{8}$ & $\frac{8}{\partial}$ & $\frac{8}{8}$ & 8 & 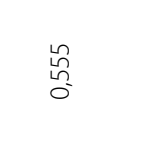 \\
\hline$\frac{1}{8}$ & 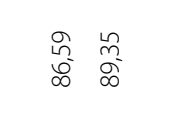 & 器器 & 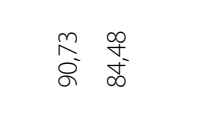 & 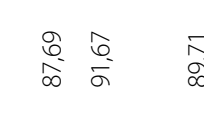 & 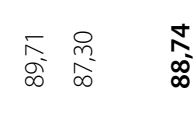 & 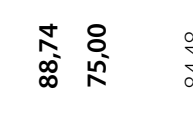 & 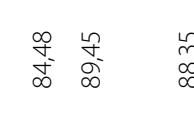 & 悬音 & 器要 \\
\hline
\end{tabular}




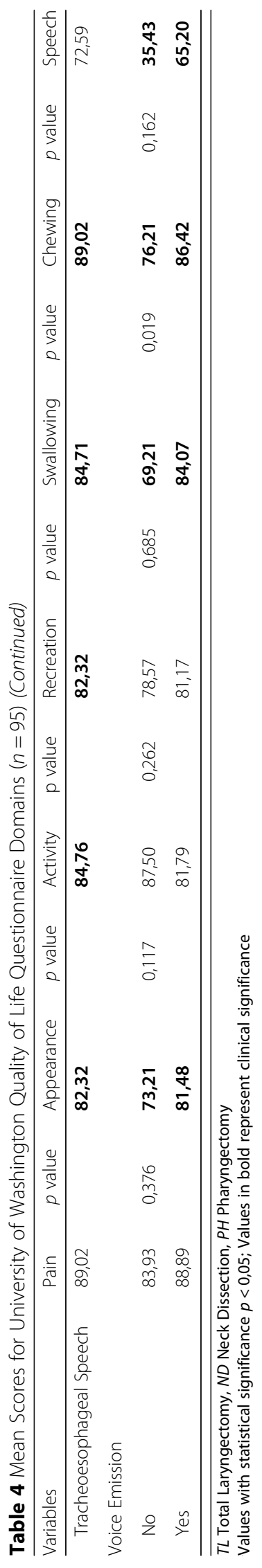




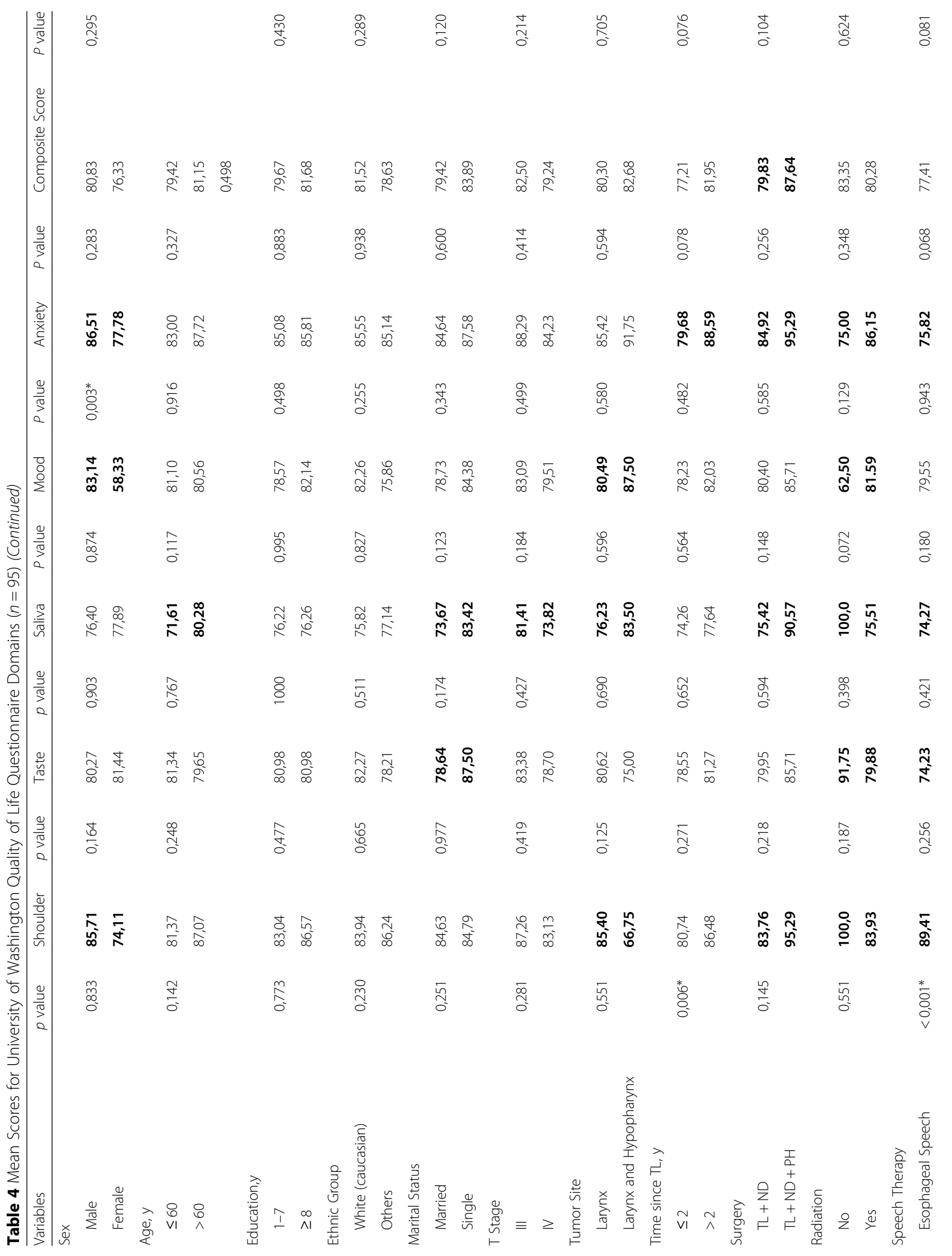




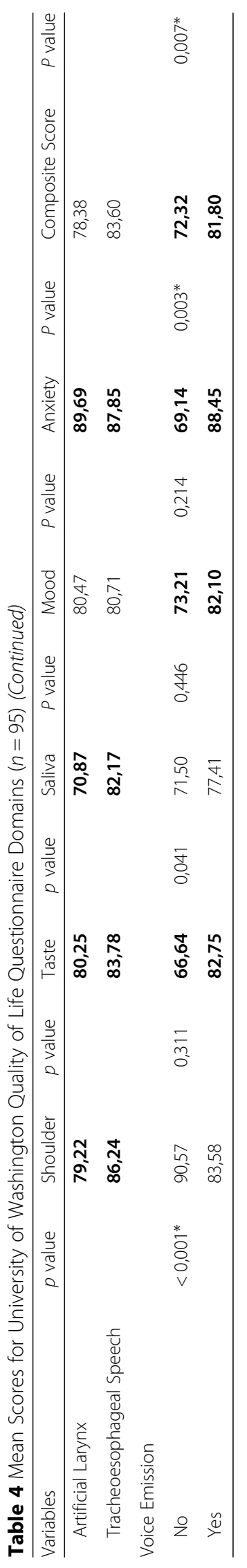


have been obtained in other studies where the patients with laryngeal cancer were mostly men and with low educational level $[3,4,14]$.

The replies to the questions concerning the subjective domains of the questionnaire showed that $78.9 \%$ of the patients considered their quality of life to be good to excellent and $90.5 \%$ indicated that their health was equal to or better than before diagnosis. These results were better than those reported in the population studied by Vartanian et al. where $59.3 \%$ of patients considered their quality of life to be good to excellent, and $74.0 \%$ indicated that their health was equal to or better than before surgery [11].

The female participants had a lower score in the mood domain, showing a greater chance of developing depression after treatment. These data were confirmed by the studies of Rogers et al. and Silveira et al. indicating that women suffer greater negative impacts on their quality of life than men $[15,16]$.

Although the health-related quality of life of patients treated with total laryngectomy tends to decline during treatment, it stabilizes at around 12 months post-surgery [3]. In a recent study on the importance of UW-QOL domains for head and neck cancer patients, Metcalfe et al. demonstrated that in the first 12 months after treatment there is a minor oscillation of items that patients consider important. However, after this period, patients attach greater importance to the swallowing, chewing and speaking domains, a tendency that continues along their life time [17].

In the study conducted by Eadie and Bowker [18], higher quality of life scores were associated with postsurgical times greater than 2 years. This was mainly for the speech domain, which is in agreement with the observations by Metcalfe et al. [17] and may be related to the possibility of better speech and language rehabilitation methods nowadays. Also, those who had more effective vocal emission at the interview were less anxious and evaluated their quality of life better in relation to their swallowing and speech than others.

After total laryngectomy, patients need to learn a new form of oral communication and how to deal with changes in breathing and swallowing. Although the literature shows that a large part of these patients have managed to overcome these challenges in 12 months after total laryngectomy, there are still some individuals who suffered a significant impact on their quality of life in the long term $[3,16,17]$. Quality of life questionnaires are focused on the dysfunctions resulting from the treatments over a short period of time. They do not contemplate the adaptation and cognitive coping that occurs over a longer time period, which may lead to an incongruity between the dysfunctions observed in the patients and the meaning in their lives [19].
Compared to the electrolarynx and the esophageal voice, patients who used the tracheoesophageal prosthesis had significantly better UW-QOL scores in speech. These results suggest that the tracheoesophageal prosthesis can be considered the best method of speech and language rehabilitation, resulting in a better quality of life and better vocal satisfaction. These data are in agreement with Oozeer et al. [3] and Balm et al. [20], who affirm that the restoration of the voice through the tracheoesophageal prosthesis offers the best possibility of oral communication for patients who have undergone total laryngectomy, and should be considered the gold standard for vocal rehabilitation. The preference for the vocal prosthesis also lies in the fact that this device can be implanted at the time of total laryngectomy [21].

In the present study the type of surgery did not influence the appearance domain, although a negative impact was expected for patients undergoing extensive treatments because of the liability to incur major cosmetic defects as well as physical and functional sequelae. Gill et al. conducted a study comparing groups of patients with head and neck cancer, their caregivers, and health care staff about their concerns and the most important aspects related to treatment. The appearance was considered a factor of great importance only for the health care group, showing that, in agreement with the results presented here, for the patients or their companions the concern with appearance was not so important [22].

Major et al. performed a study with 24 patients comparing who underwent total laryngectomy followed by radiation therapy and patients who received concomitant chemotherapy and radiation therapy [23]. The study showed that patients who did received surgery were more limited in their activities of daily living than the other group. In the same aspect, a study conduced by Guibert et al. evidenced that is a little difference in quality of life betweenpatients with total laryngectomy or organ conservation [24]. Unlike these studies, ours did not compare non-surgical with surgical patients. The focus of our study was the evaluation of quality of life according to the different methods of vocal rehabilitation in total laryngectomized patients, with time interval up to interviews over 2 years, similar to the aforementioned studies.

The only variable that influenced the quality of life composite score was the voice. The mean composite score of patients without vocal emission was 9 points less in relation to those with vocal emission. A study by Eadie and Bowker in 2012 demonstrated that the use of the traditional variables from the literature is not sufficient to establish associations with the quality of life domains [18].

The present study demonstrated that the UW-QOL questionnaire is an important evaluation tool and its 
incorporation into clinical practice is of great relevance because it can help to improve and measure the effectiveness of the treatments and their sequels. The quality of life of these patients can be improved through interventions that support the impact of the disease and its treatments $[25,26]$. In this work we were able to compare the three groups of vocal rehabilitation through the questionnaire and to prove the superiority of the tracheoesophageal prosthesis in our population, justifying the investment of tracheoesophageal prosthesis, which only the Brazilian National Cancer Institute provides for free.

Other public hospitals in Brazil have limited access to this method, and because it is the hospital of reference for cancer treatment, it is important that Brazilian National Cancer Institute reaffirm that this method of vocal rehabilitation is superior and necessary for the better quality of life of total laryngectomized patients.

The importance of incorporating quality of life into daily practice and the need for a multidisciplinary team trained and coherent in the oncological treatment aimed at the integral care of the patients should be emphasized [25]. Prior identification of concerns, depression and anxiety in patients with cancer of head and neck is of great importance because depression is underdiagnosed in cancer patients $[26,27]$. Another factor that could influence a patient's quality of life is the fear of a relapse, characterized by the fear of the cancer returning, which according to Ghazali et al. is present in $35 \%$ of patients who have survived cancer [28].

This study had some strengths, since it focused on one of the main tumor sites in the head and neck area, and the patients were grouped according to the different methods of speech and language rehabilitation methods that are carried out at the Brazilian National Cancer Institute (INCA).

However, in order to minimize the information and selection biases, the data collection was performed by a single researcher and the scores were measured by an evaluator trained to use this QOL instrument, but who was not part of the research team. Furthermore due to the low incidence of this treatment and its pathology in Brazil, the patients chosen to participate were those who had undergone the surgical procedure before the beginning of the study (December 2009). One limitation of this study may be related to recall bias, since the patients included had undergone the surgical procedure before the beginning of the study (december 2009), and in majority were interviewed more than 2 years after the procedure. This can also be connected with cognitive bias, once most of the patients were younger than 60 years, with the long-term therapy and rehabilitation, this patients may refer a better QOL due to feel more greatful to be alive despite the functional and aesthetic difficulties.
A limitation due to the cross-sectional design used is that the patients included in the study may not be representative of the total population of the patients who underwent treatment at NCI, but those who survived it. Another possible limitation is the fact that quality of life was measured after treatment and these patients could have already presented a loss of QOL at the time they were diagnosed with cancer.

As in the present study, few studies have examined the psychosocial variables and their relationships with quality of life, such as coping, which has shown to be an important association with quality of life in the literature. Coping strategies are cognitive and behavioral efforts used to deal with internal and external demands of stressful circumstances. Individuals use different coping patterns in different circumstances [29].

Despite the methodological limitations inherent to the design, the results were able to describe the general aspects of the quality of life in this population of the Institute. These results can be used in the planning and evaluation of actions for patients undergoing treatment for head and neck cancer.

\section{Conclusions}

The population included in the study was mostly composed of men of low educational level with clinical staging IV, who had undergone total laryngectomy with cervical emptying, adjuvant radiotherapy and predominantly rehabilitated with tracheoesophageal prosthesis. At the time of the interview, vocal emission was observed in most patients. There was a significant improvement in quality of life after treatment, and the majority of the patients considered the quality of life at the time of the interview good to excellent.

The results showed that the worst quality of life scores for patients who had undergone total laryngectomy were in the domains for mood, activity, rehabilitation with the esophageal voice and lack of vocal emission. The high mean value of the composite score for quality of life revealed that the patients assessed their quality of life positively. The absence of vocal emission was the only variable associated with a lower quality of life within the composite score according to the UW-QOL questionnaire.

\section{Abbreviations \\ IBM: International Business Machines Corporation; ICD-O: International Classification of Diseases for Oncology; QOL: Quality of Life; SCC: Squamous cell carcinoma; SPSS: Statistical Product and Service Solutions; UICC TNM classification: The UICC TNM Classification is an anatomically based system that records the primary and regional nodal extent of the tumor and the absence or presence of metastases. Each individual aspect of TNM is termed as a category: T category describes the primary tumor site $\mathrm{N}$ category describes the regional lymph node involvement $M$ category describes the presence or otherwise of distant metastatic spread; UW-QOL: University of Washington Quality of Life Questionnaire; WHO: World Health Organization}

Acknowledgements Not applicable. 


\section{Authors' contributions}

FGRS is the first author of this paper, was involved in conception study and design, in acquisition of data and interpretation, manuscript preparation, editing and review. ICS was involved in conception study concepts and design, data interpretation, manuscript preparation, editing and review. $A B$ was involved in data analysis and interpretation, quality control of data and algorithms and statistical analysis. LCST was involved in quality control of data and algorithms and statistical analysis. ASF was involved in data collection and data analysis and interpretation, manuscript preparation. EQF was involved in manuscript preparation and review. FLD is the chief of this group, was involved in developing study concepts and design and revising manuscript critically. All authors have read and approved the final manuscript.

\section{Funding}

This study were made in a Public National Institute and all steps and costs of this research were already contemplated in Head and Neck Practice Routine.

\section{Availability of data and materials}

Please contact author for data requests.

\section{Ethics approval and consent to participate}

Ethical approval for this study was given by the Ethics and Research Committee of the Brazilian National Cancer Institute set in the context of service evaluation under number 96/09.

\section{Consent for publication}

Not applicable.

\section{Competing interests}

The authors declare that they have no competing interests.

\section{Author details}

${ }^{1}$ Researcher Psychologist from Department of Head and Neck Surgery, Brazilian National Cancer Institute, INCA, Praça da Cruz Vermelha, 23, Rio de Janeiro 20230-130, Brazil. ${ }^{2} \mathrm{Head}$ and Neck Surgeon from the Department of Head and Neck Surgery, Brazilian National Cancer Institute, Rio de Janeiro, Brazil. ${ }^{3}$ Clinical Research and Technology Incorporation Coordination, Brazilian National Cancer Institute, Rio de Janeiro, Brazil. "Speech-Language Pathologist from Department of Head and Neck Surgery, Brazilian National Cancer Institute, Rio de Janeiro, Brazil.

Received: 23 June 2017 Accepted: 30 January 2020

Published online: 03 April 2020

\section{References}

1. GLOBOCAN (IARC). Section of Cancer Surveillance; 2012. [updated 09 Oct 2014]. Avaliable from: http//globocan.iarc.fr/Pages/fact_sheets_population.aspx.

2. Instituto Nacional De Câncer José Alencar Gomes Da Silva. Coordenação de Prevenção e Vigilância. Estimativa 2018: Incidência do Câncer no Brasil. Rio de Janeiro: INCA; 2017. Portuguese.

3. Oozeer NB, Owen S, Perez GJ, Welch AR, Paleri V. Functional status after total laryngectomy: cross-sectional survey of 79 laryngectomees using the performance status scale for head and neck Cancer. J Laryngol Otology. 2010;124:412-6.

4. Williamson JS, Ingrams $D$, Jones $H$. Quality of life after treatment of laryngeal carcinoma: a single Centre cross-sectional study. Ann R Coll Surg Engl. 2011;93:591-5.

5. World Health Organization. Measuring Quality of Life [Internet]. Available at: https://www.who.int/healthinfo/survey/whoqol-qualityoflife/en/. Accessed 30 Mar 2020.

6. Rogers SN, Lowe D. Screening for dysfunction to promote multidisciplinary intervention by using the University of Washington Quality of life questionnaire. Arch Otolaryngol Head Neck Surg. 2009;135(4):369-75.

7. Hassan SJ, Weymuller EA Jr. Assessment of quality of life in head and neck cancer patients. Head Neck. 1993;15:485-96.

8. Laraway DC, Rogers SN. A structured review of journal articles reporting outcomes using the University of Washington Quality of life scale. Br J Oral Maxillofac Surg. 2012;50:122-31.

9. Vartanian JG, Carvalho AL, Furia CLB, Junior GC, Rocha CN, et al. Questionnaires validated in the Brazilian population for evaluation of the quality of life in patients with head and neck cancer. Rev Bras Cir Cabeça Pescoço. 2007;36(2):108-15.

10. Aaronson NK, Ahmedzai S, Bergman B, Bullinger M, Cull A, Duez NJ, Filiberti A, Flechtner H, Fleishman SB, de Haes JC. The European Organization for Research and Treatment of Cancer QLQ-C30: a quality-of-life instrument for use in international clinical trials in oncology. J Natl Cancer Inst. 1993;85(5): $365-76$.

11. Vartanian JG, Carvalho AL, Yueh B, Furia CLB, Tayota J, McDowell JA, et al. Brazilian-Portuguese validation of the University of Washington Quality of life questionnaire for patients with head and neck cancer. Head Neck. 2006; 10:1115-21.

12. Brierley J (ed), Gospodarowicz MK (ed), Wittekind C (ed). TNM classification of malignant tumours. 8th edition. Oxford and Hoboken: Wiley; 2017.

13. Weymuller EA, Yueh B, Deleyiannis FWB, Kuntz AL, Alsarraf R, Coltrera MD. Quality of life in patients with head and neck Cancer: lessons learned from 549 prospectively evaluated patients. Arch Otolaryngol Head and Neck Surg. 2000;126(3):329-36.

14. Silveira AP, Gonçalves JJ, Sequeira T, Ribeiro C, Lopes C, Monteiro E, et al. Patient reported outcomes in head and neck cancer: selecting instruments for quality of life integration in clinical protocols. Head Neck. 2010;2:32.

15. Rogers SN, Lowe D, Yueh B, Weymuller EA Jr. The physical function and social-emotional function subscales of the University of Washington Quality of life questionnaire. Arch Otolaryngol. Head Neck Surg. 2010;136(4):352-7.

16. Silveira AP, Gonçalves JJ, Sequeira T, Ribeiro C, Lopes C, Monteiro E, et al. Geriatric oncology: comparing health related quality of life in head and neck cancer patients. Head Neck. 2011;3:3.

17. Metcalfe CW, Lowe D, Rogers SN. What patients consider important: temporal variations by early and late stage oral, oropharyngeal and laryngeal subsites. J Craniomaxillofac Surg. 2014;42:641-7.

18. Eadie TL, Bowker BC. Coping and quality of life after Total Laryngectomy. Otolaryngol Head Neck Surg. 2012;146(6):959-65.

19. Ghazali N, Lowe D, Rogers SN. Enhanced patient reported outcome measurement suitable for head and neck cancer follow-up clinics. Head Neck Oncology. 2012;4:32.

20. Balm AMJ, Van den Brekel MWM, Tan IB, Hilgers FJM. The indwelling voice prosthesis for speech rehabilitation after total laryngectomy: a safe approach. Otolaryngol Pol. 2011;65(6):402-9.

21. Van der Molen L, Kornman AF, Latenstein MN, Van den Brekel MW, Hilgers FJ. Practice of laryngectomy rehabilitation interventions: a perspective from Europe/the Netherlands. Curr Opin Otolaryngol Head Neck Surg. 2013;21(3): 230-8.

22. Gill SS, Frew J, Fry A, Adam J, Paleri V, Dobrowsky W, et al. Priorities for the head and neck Cancer patient, their companion and members of the multidisciplinary team and decision regret. Clin Oncol. 2011;23:518-24.

23. Major MS, Bumpous JM, Flynn MB, Schill K. Quality of life after treatment for advanced laryngeal and hypopharyngeal cancer. Laryngoscope. 2001;111(8): 1379-82.

24. Guibert M, Lepage B, Woisard V, Rives M, Serrano E, Vergez S. Quality of life in patients treated for advanced hypopharyngeal or laryngeal cancer. Eur Ann Otorhinolaryngol Head Neck Dis. 2011;128(5):218-23.

25. Gonçalves JJ, Rocha AM. A decision support system for quality of life in head and neck oncology patients. Head Neck. 2012;4:3.

26. Lang H, France E, Williams B, Humphris G, Wells M. The psychological experience of living with head and neck cancer: a systematic review and meta-synthesis. Psycho-Oncology. 2013;22:2648-63.

27. Kanatas A, Ghazali N, Lowe D, Rogers SN. The identification of mood and anxiety concerns using the patients concerns inventory following head and neck cancer. J Oral Maxillofac Surg. 2012;41:429-36.

28. Ghazali N, Cadwallader E, Lowe D, Humphris G, Ozakinci G, Rogers SN. Fear of reccurrence among head and neck cancer survivors: longitudinal trends. Psycho-Oncology. 2013;22:807-13.

29. Montazeri A. Quality of life as prognostic indicators of survival in cancer patients: an overview of the literature from 1982 to 2008. Health Qual Life Outcomes. 2009;7:102.

\section{Publisher's Note}

Springer Nature remains neutral with regard to jurisdictional claims in published maps and institutional affiliations. 